\title{
Articles
}

\section{Beliefs About Finding a Compatible Partner in Three Settings}

\author{
Susan Sprecher*a
}

[a] Department of Sociology \& Anthropology, Illinois State University, IL, Illinois, USA.

\begin{abstract}
Single adults often exert considerable energy searching for a compatible partner. Until recently, people met partners primarily through everyday activities (work, school) and through friends. These ways of meeting partners are still common, although Internet dating sites have also become a main way for couples to meet. The current study was conducted to examine people's attitudes about finding a compatible partner in three different settings: online dating, the social network (e.g., friends of friends), and everyday activities. A sample of 702 single (unpartnered) adults (ages 18 to 40) completed a survey that included items that measured their attitudes about finding a compatible partner in the three different ways. Participants believed they would be less likely to find a compatible partner through online dating than either through friends or in everyday activities. Age and shyness were negatively associated with optimism of finding a partner, particularly in the traditional settings of everyday activities and through one's social network.
\end{abstract}

Keywords: mate-searching, internet dating, shyness, finding a compatible partner

Interpersona, 2019, Vol. 13(2), 253-264, https://doi.org/10.5964/ijpr.v13i2.346

Received: 2019-01-25. Accepted: 2019-10-16. Published (VoR): 2020-01-06.

${ }^{*}$ Corresponding author at: Department of Sociology \& Anthropology, Illinois State University, 4660, Schroeder Hall 332, Normal, IL 61790, USA. E-mail: sprecher@ilstu.edu

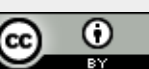

This is an open access article distributed under the terms of the Creative Commons Attribution 4.0 International License, CC BY 4.0 (https://creativecommons.org/licenses/by/4.0/), which permits unrestricted use, distribution, and reproduction in any medium, provided the original work is properly cited.

One task in adolescence and emerging adulthood is to form intimate relationships (Arnett, 2000, 2015; Erikson, 1968). With the median age of marriage currently now 27 (females) and 29 (males) (Centers for Disease Control and Prevention, 2017), however, the time of seeking intimate partners spans many years including beyond early adulthood. Many adults enter and exit relationships frequently before they move toward a commitment (LeFebvre \& Carmack, 2019). For single (unpartnered) adults who desire to enter a romantic relationship, many more opportunities exist today than in the past for finding a partner. Traditionally, people met partners primarily through everyday activities (school, work) and through friends (Laumann, Gagnon, Michael, \& Michaels, 1994). These are still common ways to meet partners (Sassler \& Miller, 2015), but the Internet has become another popular mate-seeking venue (Rosenfeld \& Thomas, 2012; Rosenfeld, Thomas, \& Hausen, 2019; Smith \& Duggan, 2013). In fact, a recent national study of couple formation indicates that the Internet has surpassed friends as the major way of meeting partners (Rosenfeld et al., 2019). Although there are many specific online venues for meeting partners, including online games and social media, online dating sites (e.g., Match.com) and phone apps (e.g., Tinder) are currently becoming common ways for singles to meet partners (Finkel, Eastwick, Karney, Reis, \& Sprecher, 2012; Rosenfeld, 2018). 
The increase in online venues for meeting romantic partners has been seemingly accompanied by greater demands for a partner (Bruch \& Newman, 2018). Marriage scholars have noted that people expect more from marriage and other intimate relationships than ever before (Finkel, Hui, Carswell, \& Larson, 2014; Neff \& Morgan, 2014). People want their partner to possess many desirable characteristics, be compatible with them, and help them fulfill their personal growth needs. With the greater number of opportunities to find a partner and the increasing demands to find an ideal partner or soulmate (Houran \& Lange, 2004), people are likely to analyze their options and choose settings that can maximize their mate-searching efforts. Furthermore, there are likely to be individual differences in beliefs about finding a compatible partner, both overall and in regard to specific mate-seeking settings. That is, some people likely are more optimistic than others that they will find a compatible partner overall; furthermore, people may have more optimism about finding partners in some settings than others.

The purpose of this study was to examine the beliefs of single (unpartnered) adults about the efficacy of finding a compatible partner in three common mate-searching settings: online dating, one's social network, and through everyday activities. Recent research has documented where and how people meet their partners (e.g., Rosenfeld \& Thomas, 2012; Rosenfeld et al., 2019), but almost no research has examined people's beliefs about the likelihood they will find a compatible partner in specific settings. The exception is recent research on people's attitudes about finding a partner specifically through online dating. Although the first studies on this topic indicated that there were widespread negative attitudes about meeting partners through online dating sites (Orr, 2004), it has been noted that the stigma of Internet dating has decreased (Finkel et al., 2012; Smith \& Duggan, 2013). For example, in a national study, Smith and Duggan (2013) found that 59\% of all Internet users said "online dating is a good way to meet people" (up from 44\% in 2005). In addition, 53\% of their Internet users reported that "online dating allows people to find a better match for themselves." However, whether people now believe they are more likely to find a compatible partner through Internet dating sites compared to in traditional ways, such as through friends and everyday activities, has not been considered with standardized questions assessed similarly for each of several settings. Certainly, online dating sites claim that they offer a superior way to find a compatible partner (Finkel et al., 2012), but whether people believe this to be the case is an empirical question that has not been investigated. Therefore, the following research question is posed:

Q1A: How optimistic are people about finding a compatible partner, overall, and how does the degree of optimism vary across each of three settings: online dating, through one's social network, and through everyday activities?

\section{Individual Differences in Optimism of Finding a Compatible Partner in Three Settings}

This study also considers how attitudes about finding a partner in the three settings are likely to vary with individual difference variables, and focuses specifically on age and shyness. Young adults (college age) are often surrounded by potential partners in classes and social events. After leaving college, however, there can be fewer opportunities to find partners in everyday activities and through social networks. In fact, social networks have been found to reduce in size after college (Reis, Lin, Bennett, \& Nezlek, 1993). Therefore, people beyond college age - due to life changes such as shrinking networks, busy work schedules, and fewer available partners in everyday settings - may be less optimistic in general about finding a partner, as compared to younger adults. However, post-college age adults may recognize the value of the affordances offered through online dating websites to a greater degree than younger adults. As noted by Rosenfeld and Thomas (2012), internet search- 
ing for romantic partners may be especially important for people who have "thin markets," including singles in their 30 s and 40 s at least as compared to those who are college age.

Suggestive evidence exists that age (at least up to middle-age) is associated with more positive attitudes about Internet dating. In an early study, Donn and Sherman (2002) found that graduate students (mean age of 30) had a less negative attitude about using the Internet to meet potential partners than did undergraduate students (ages 18 to 20). Thus, attitudes about finding a partner through online dating may be more positive for people as they approach middle-age. Age may be associated negatively, however, with beliefs about finding a partner in more traditional settings, such as through friends in everyday life. In a survey study with Internet users, Stephure, Boon, MacKinnon, and Deveau (2009) examined the association between age and involvement in online dating, an association that was found to be positive. As part of the study, they asked the participants to rate their satisfaction with "traditional means of meeting people (i.e., through friends, bars or clubs, church, etc.)." A substantial negative correlation was found between age and satisfaction with non-Internet methods of meeting people $(r=-.43)$. In general, age may be associated negatively with optimism about finding a compatible partner in existing dating markets, with the exception that people in their late 20s and 30s may be more positive than younger participants about finding a partner through online dating. The first hypothesis is:

H1: With increasing age: (a) optimism about finding a compatible partner will decrease, although (b) the association will be less strong and possibly even reversed (positive) for the setting of Internet dating.

Shyness is another individual difference variable that is likely to be associated with less optimism about finding a compatible partner in a variety of settings. Shy people can be self-conscious and uncomfortable around others and fear negative evaluations and rejection by others (Cheek \& Buss, 1981; Henderson, Gilbert, \& Zimbardo, 2014; Ickes, 2009; Jackson, Fritch, Nagasaka, \& Gunderson, 2002). Past research has shown that shyness is associated with a lack of social and communication skills (Arroyo \& Harwood, 2011; Ickes, 2009) and with difficulties in face-to-face social interaction (Arkin \& Grove, 1990), including initiating conversations (Cheek \& Buss, 1981; Manning \& Ray, 1993). Furthermore, shyness has been found to be correlated negatively with self-reports of dating competence and assertiveness (LeSure-Lester, 2001) and associated with minimal (low frequency) dating in college (Leck, 2006). Shyness has also been found to be associated with remaining single through emerging adulthood (Schneier et al., 1994; as cited in Wenzel \& Emerson, 2009).

A stereotype in the first years of the existence of Internet dating was that shy people (and those with other social deficiencies, such as loneliness) would turn to Internet dating to find partners. Very little evidence, however, has been found for what has been referred to in the literature as the "social compensation hypothesis," the argument that people who have social or dating anxiety may benefit the most from the option to find a partner online (Orr, 2004; Valkenburg \& Peter, 2007). The opposite hypothesis is "the rich get richer," which states that those who are skilled at dating and interaction use the Internet as just one more strategy to find a partner (Valkenburg \& Peter, 2007).

In a study of Dutch singles, Valkenburg and Peter (2007) found evidence that Internet daters who were lower in dating anxiety used the Internet more often to find a partner than those higher in dating anxiety, suggesting support for "the rich get richer" proposition. In addition, a large survey study of U.S. residents (ages ranged from 19 to 80, with a mean age of 48), collected in 2004 from members of the Market Facts' Consumer Mail Panel, found that those who had engaged in Internet dating scored higher on a measure of sociability compared to those who had not engaged in Internet dating (Kim, Kwon, \& Lee, 2009). Furthermore, a German sam- 
ple of 437 adults, aged 17 to 69 (mean age of 32), found that online daters did not differ from non-online daters in shyness (as well as self-esteem, emotional stability, and openness) (Aretz, Demuth, Schmidt, \& Vierlein, 2010). Only one difference was found: on-line daters scored higher on introversion (or lower on extroversion). On the other hand, Whitty and Buchanan (2009) found that those who scored high on shyness (relative to those who scored lower) were more likely to have tried online dating, based on a sample of UK and U.S. participants obtained through various websites. It should also be noted that in a much earlier study, Goodwin (1990) found that members of a British dating service (not online) scored lower on dating skills and assertiveness than a comparison group; and Scharlott and Christ (1995), in data collected from 1990, found that shy individuals were drawn to online dating that existed at the time (which was more text-based). Shy people may have been drawn to early forms of online dating, but now that Internet dating sites are more mainstream and emphasize communication across modalities and involve moving quickly to a face-to-face meeting, there may no longer be a special attraction to online dating among those who are anxious about social interactions.

However, the existing research has focused more specifically on the characteristics (e.g., shyness) of those who have engaged in Internet dating and not on how individual difference variables are associated with attitudes about finding a compatible partner in different settings. One exception is a study by Poley and Luo (2012), who had a sample of college students complete several measures of social deficiencies (e.g., dating anxiety, attachment anxiety), several measures of social competencies (e.g., extraversion, social skills), and measures of actual use of and attitudes toward both online dating and face-to-face dating. An example item to measure attitudes toward online dating was, "I think the Internet is a great place to find someone to be in a relationship with." Poley and Luo found that both socially competent participants and socially incompetent participants had a more positive attitude toward face-to-face dating than online dating. The sample, however, was limited to young adults, and the items to measure attitudes toward online dating were not parallel equivalents to the items used to measure attitudes toward face-to-face dating.

Therefore, the present study, which includes a diverse sample of single adults from age 18 to 40 and parallel measures of attitudes about finding a partner in different venues, provides a unique test of how shyness is associated with beliefs about finding a partner in different settings. The second hypothesis is:

H2: Shyness will be: (a) negatively associated with overall optimism about finding a compatible partner, although (b) the association will be less strong and possibly reversed (positive) for the setting of Internet dating.

In examining the effect of age and shyness on optimism for finding a partner, multiple regression analyses are conducted to examine the unique effects of each, controlling for the other variable. The analysis also controls for sex (male-female). Although, there are no theoretical or empirical reasons to predict that men and women have different optimism levels in regard to finding a compatible partner in the different settings, this issue is considered as a research question:

$R Q 2:$ Controlling for age and shyness, are there sex differences in optimism about finding a compatible partner, overall, and in each of the three settings: online dating, through one's social network, and through everyday activities? 


\section{Method}

\section{Sample}

The sample consisted of 702 single adults (62\% women) who: (1) identified themselves as currently single and not in a relationship; (b) were 40 years of age or younger (thus, emerging adulthood through the start of middleage); and (3) completed all or most of the measures for this study. Participants were obtained in diverse ways, including a U.S. Midwest public university, and several online venues, as discussed further below in the Procedure section.

The ages of the participants included in the sample ranged from 18 to 40 , with a mean age of 23.97 $(S D=5.31)$. In regard to race, $75.9 \%$ identified themselves as White, $11.4 \%$ reported Black, $6.8 \%$ reported Latino/Hispanic, and $5.6 \%$ reported Asian.

\section{Procedure}

A paper survey and an identical online survey were created. The subsample (26\%) for the paper survey was obtained mostly via several social science classes at a Midwest university. Students were told to complete the survey only if they were currently single and unattached (students who were in a relationship were given an alternative survey to complete). Participants received extra credit for completing a survey, but had the option of a non-research activity for earning credit.

A link to the online version of the survey (completed by $76 \%$ of the sample) was distributed to several groups of individuals. First, in some classes at the Midwest University, students were given the option by the instructor to complete the online survey outside of class for extra credit ( $20 \%$ of the online participants). Second, a snowball sample was obtained through research team members given the option to post the survey on social media ( $36 \%$ of the online participants). Third, data were collected from Amazon's Mechanical Turk ( $30 \%$ of the online participants); these participants were paid one dollar for completion of the survey. Fourth, a small group ( $7 \%$ of the online participants) were obtained because they were given the survey as an option for earning research credit when arriving for a different study in the author's research lab that required two participants (but the other participant did not arrive). Fifth, the link to the survey was posted for a brief time at the Science of Relationships website (currently https://www.luvze.com); $5 \%$ of the online participants came from this source. Finally, other online participants checked "Other," and the exact way they reached the survey link could not be determined. The percentage from each of these sources is an estimate because not all participants identified the way they reached the online link to the survey.

\section{Measures}

As part of a longer survey targeted to single adults, ${ }^{\text {ii }}$ participants responded to a set of items on their attitudes about finding a partner in different settings. More specifically, they were asked their attitudes about the likelihood that they could find a compatible partner in three different settings: an online dating website, their social network (friends of friends), and daily activities (work, school, hobbies). Three specific questions were asked for each of the above settings: (1) "How easy do you think it would be to meet a romantic partner through/in ?" (2) "How likely do you believe it would be that you would meet a dating partner with the characteristics that you desire through/in ?" (3) "If you were to spend time looking for a partner through/in 
how likely do you believe you would find someone compatible with you?" (See Spielmann et al., 2013, Study 6, for two similar items in regard only to online dating.) The items were followed by response options that ranged from 1 (very unlikely, not all easy) to 7 (very likely, very easy). For each setting, a composite score was created based on the mean of the three items. The higher the composite score, the more optimistic the participants were about finding a compatible partner in that particular setting. Cronbach's Alpha for each of the three composite scores were .82 (Internet dating), .87 (social network), and .90 (daily activities). In addition, a grand composite score was created that combined the responses to all nine items, with a higher score indicating greater optimism of finding a partner across all settings $(\alpha=.83)$.

Participants also completed six items from the Cheek and Buss (1981) revised shyness scale (see, also, Cheek, 1983; Hopko, Stowell, Jones, Armento, \& Cheek, 2005). We included such items as "It does not take me long to overcome my shyness in new situations" [reverse scored] and "I am socially somewhat awkward.").iii Participants responded to each item on a $1=$ does not describe me; to $7=$ describes me completely. A composite score was created based on the mean of the items (after reverse scoring two items). Higher scores represented greater shyness. Cronbach's Alpha was .86.

\section{Results}

\section{Optimism About Finding a Partner, Overall and in Three Settings}

The mean score of overall optimism about finding a compatible partner was $3.95(S D=1.04)$, indicating that the participants believed that they would have moderate success across the three settings in finding a compatible partner. To address $R Q 1$ (i.e., whether there would be differences in optimism for finding a compatible partner as a function of the type of setting), a repeated measures ANOVA was conducted to compare the optimism scores in the three settings. A significant effect was found for type of setting, $F(2,700)=30.19, p<.001$; partial eta-squared $=.079$. The mean score was highest for optimism about finding a partner through one's social network $(M=4.16, S D=1.44)$, followed by optimism about finding a partner through everyday activities $(M=4.03$, $S D=1.49$ ). Both scores were significantly higher than the mean optimism score for finding a partner through online dating $(M=3.66, S D=1.38)$, paired ts were 7.78 and 5.20 , respectively (both $p<.001$, with Cohen's $d$ of .29 and .20). There was also a modest significant difference between the optimism scores for finding a partner through one's social network versus in everyday activities (using a protected significance level of $.05 / 3=.017$ ), but the difference was modest and the effect size was small (paired $t=2.42, p=.016$; Cohen's $d=.09$ ).

\section{Individual Difference Predictors of Optimism About Finding a Partner}

To examine how the individual difference variables are associated with optimism about finding a compatible partner, a series of multiple regression analyses were conducted that allow for the examination of the unique variance explained by each predictor. ${ }^{\mathrm{iv}}$ The results are presented in Table 1 in four panels (the overall composite score, and the optimism scores for each of the three settings). Sex was coded as a dummy variable (male $=0$; female =1). Age and shyness were continuous variables.

In the prediction of overall optimism (the composite score across settings, as presented in the top panel of the table), sex did not explain any unique variance (RQ2). As hypothesized, however, both age (H1) and shyness 
Table 1

Regression Analysis Summary for Predicting Optimism of Finding a Partner, Overall and in Each of Three Settings

\begin{tabular}{|c|c|c|c|c|c|}
\hline Predictor Variable & B & $95 \% \mathrm{Cl}$ [LL, UL] & $\beta$ & $t$ & $p$ \\
\hline \multicolumn{6}{|c|}{ Overall Optimism (Across the Settings) } \\
\hline Sex $($ Males = 0; Females $=1)$ & -.11 & {$[-.26, .04]$} & -.05 & -1.45 & .147 \\
\hline Age & -.06 & {$[-.07,-.05]$} & -.30 & -8.52 & $<.001$ \\
\hline Shyness & -.22 & {$[-.27,-.17]$} & -.30 & -8.52 & $<.001$ \\
\hline \multicolumn{6}{|c|}{$R^{2}=.198 ; F(3,681)=56.00, p<.001$. } \\
\hline \multicolumn{6}{|c|}{ Overall Optimism (through Online Dating) } \\
\hline Sex $($ Males $=0 ;$ Females $=1)$ & -.14 & {$[-.35, .08]$} & -.05 & -1.22 & .222 \\
\hline Age & -.01 & {$[-.03, .01]$} & -.04 & -1.01 & .311 \\
\hline Shyness & -.16 & {$[-.24,-.09]$} & -.17 & -4.37 & $<.001$ \\
\hline \multicolumn{6}{|c|}{$R^{2}=.032 ; F(3,681)=7.61, p<.001$} \\
\hline \multicolumn{6}{|c|}{ Overall Optimism (through Social Network) } \\
\hline Sex $($ Males $=0 ;$ Females $=1)$ & .02 & {$[-.19, .23]$} & .01 & .23 & .821 \\
\hline Age & -.08 & {$[-.10,-.06]$} & -.30 & -8.41 & $<.001$ \\
\hline Shyness & -.27 & {$[-.34,-.20]$} & -.26 & -7.39 & $<.001$ \\
\hline \multicolumn{6}{|c|}{$R^{2}=.18 ; F(3,681)=49.94, p<.001$} \\
\hline \multicolumn{6}{|c|}{ Overall Optimism (through Everyday Activities) } \\
\hline Sex $($ Males $=0 ;$ Females $=1)$ & -.22 & {$[-.44, .00]$} & -.07 & -1.94 & .05 \\
\hline Age & -.09 & {$[-.11,-07]$} & -.31 & -8.50 & $<.001$ \\
\hline Shyness & -.23 & {$[-.31,-.16]$} & -.22 & -6.11 & $<.001$ \\
\hline
\end{tabular}

$(H 2)$ were unique and negative predictors of optimism about finding a partner, overall. Older participants (within the age range of 18 to 40 ) and shyer participants were less optimistic about finding a partner.

The other three panels in the table present the multiple regression results for optimism for finding a partner in each setting. Shyness was a consistent, negative predictor of optimism, regardless of the specific setting. The negative effect of shyness was strongest for optimism of finding a compatible partner through one's social network, but was also found to be highly significant in the other two settings. Age was a significant (negative) predictor of optimism for finding a partner in the settings of social network and everyday activities, but not for online dating. Sex was not a significant predictor (at the protected significance level of $p<.016$ ) for any of the settings, controlling for age and shyness.

\section{Discussion and Conclusion}

Although online dating sites have become popular in recent years (Rosenfeld et al., 2019; Smith \& Duggan, 2013) and have produced claims that they can find members a compatible partner and even one's soulmate (as discussed in Finkel et al., 2012), the present study indicates that people still have a more positive forecast about finding a compatible partner through traditional ways of meeting (daily activities and social network) than through Internet dating. Many young adults in emerging adulthood are still likely to meet partners through their 
friends and in their daily activities (e.g., classes). Even though the participants were less positive about finding a compatible partner through Internet dating than through social networks and daily activities, the composite score of attitudes toward Internet dating was around the midpoint of the scale, which could be considered to be moderate optimism.

We expected to find variation in the participants' optimism about finding a compatible partner overall and in each of the specific settings, and that the variation would be associated with certain individual characteristics. Participants' age was found to be associated with less optimistic forecasts of finding a compatible partner, although more specifically through one's social network and in daily activities. These findings are consistent with Stephure et al. (2009), who found a negative correlation between age and reported satisfaction with traditional ways of meeting partners. Young adults (e.g., 18-22) are typically surrounded by others who are single and available,; however, with increasing age through emerging adulthood and beyond, the social environment changes and there are generally fewer available others. Some experts (Rosenfeld \& Thomas, 2012) have referred to the "thin marriage markets" for people beyond young adulthood.

Interestingly, however, the participants' views about finding a compatible partner through Internet dating did not vary with age. Perhaps we would have expected views about finding a compatible partner through Internet to become even more positive with age, but the fact that the views did not become more negative with age (as did the views about finding a compatible partner in the other settings) is consistent with other prior research showing that Internet dating may be relatively important for those who are past young adulthood (e.g., Rosenfeld \& Thomas, 2012; Stephure et al., 2009).

Past research (e.g., Wenzel \& Emerson, 2009) has suggested that shy people may have a pessimistic attitude about meeting potential romantic others, and our findings confirmed this. Those who scored high on shyness were less likely to forecast that they would be able to find a compatible partner, as indicated by the composite score across the settings and by the composite scores in each of the various settings. Shy people may be aware of their deficiencies (e.g., awkwardness, lack of confidence) that they bring to interactions with others, which may contribute to their beliefs that it would be difficult to find a compatible partner. The negative effect of shyness on optimism about finding a partner online (rather than a positive association) suggests no evidence for a "social compensation hypothesis" (Orr, 2004; Valkenburg \& Peter, 2007), which would predict that people who are shy (and high in social anxiety) will use online dating to compensate for difficulties that they might have in forming relationships in FtF interaction. However, this study focused on beliefs about finding a compatible partner and did not measure actual or even desired use in different mate-seeking strategies. Shy people may differ from others more in behaviors than in attitudes in a way that would reflect the social compensation hypothesis.

A strength of this research was that it was the first study to systematically compare people's attitudes about finding a partner through Internet dating websites versus more traditional ways (social network and daily activities), using standardized measures across the settings. We also had a large and diverse sample, which included people throughout emerging adulthood into their thirties. In addition, all of the adults were currently single and not in a relationship and thus potentially seeking a relationship. Of course, as is true of all studies, there were limitations. The questions for this study were embedded in a larger, multi-purpose survey. More in-depth questions about single adults' views about finding partners in different settings could be examined in future research. In addition, attitudes about finding partners in other settings could be examined, including social media 
and mobile dating apps (e.g., Tinder), which are likely to be used especially by younger adults for finding partners (Smith, 2016). Because attitudes about Internet dating and other ways of finding compatible partners are likely to change over time, panel studies could be designed to monitor the changing attitudes about Internet dating relative to other ways of meeting partners during emerging adulthood and beyond.

Although attitudes do not always predict behavior, generally there is strong association when the specificity of the attitude matches the specificity of the behavior (Davidson \& Jaccard, 1979). If people are optimistic about finding a partner in a specific setting, they are likely to exert effort in mate-searching in that particular setting. Self-fulfilling prophecies can occur by which individuals who believe they can find a compatible partner in a setting will engage in efforts to make this happen. Of course, not all single adults want to find a relationship partner, as some may find the life of singlehood and being unpartnered most ideal for them.

\section{Notes}

i) A few others were eliminated for other reasons including not completing the attention items in the online survey or accidentally being given an earlier draft of the paper survey. In addition, because there were not many participants over the age of 40 (and they were not targeted for this study), we included only those who were age 40 or younger.

ii) The larger study had multiple purposes beyond what was investigated in this study.

iii) The decision was to include only six items (from the longer 13-item scale) primarily because of concern over the length of the survey (which included measures on other topics) and potential participant fatigue. The first six items listed in the scale were chosen. The items chosen had good psychometric properties in our data (e.g., high item-to-total correlations). Other evidence also indicates that these particular items have good psychometric properties (e.g, Crozier, 2005; Hopko et al., 2005).

iv) Shyness was positively correlated with age $(r=.13, p=.001)$. No sex differences were found in shyness $(t=-.35)$, although men in the sample had a higher mean age than women in the sample $(M=25.65$ vs. $22.94 ; t=6.78, p<.001)$; hence, it was important to control for each in a regression analysis.

\section{Funding}

The author has no funding to report.

\section{Competing Interests}

The author has declared that no competing interests exist.

\section{Acknowledgments}

The author would like to thank Samuel Fisher for assistance on data management.

\section{References}

Aretz, W., Demuth, I., Schmidt, K., \& Vierlein, J. (2010). Partner search in the digital age. Psychological characteristics of online-dating-service-users and its contribution to the explanation of different patterns of utilization. Journal of Business and Media Psychology, 1, 8-16.

Arkin, R. M., \& Grove, T. (1990). Shyness, sociability and patterns of everyday affiliation. Journal of Social and Personal Relationships, 7, 273-281. https://doi.org/10.1177/0265407590072008

Arnett, J. J. (2000). Emerging adulthood: A theory of development from the late teens through the twenties. The American Psychologist, 55, 469-480. https://doi.org/10.1037/0003-066X.55.5.469 
Arnett, J. J. (2015). Socialization in emerging adulthood: From the family to the wider world, from socialization to selfsocialization. In J. E. Grusec, P. D. Hastings, J. E. Grusec, \& P. D. Hastings (Eds.), Handbook of socialization: Theory and research (2nd ed., pp. 85-108). New York, NY, USA: Guilford Press.

Arroyo, A., \& Harwood, J. (2011). Communication competence mediates the link between shyness and relational quality. Personality and Individual Differences, 50, 264-267. https://doi.org/10.1016/j.paid.2010.09.041

Bruch, E. E., \& Newman, M. E. J. (2018). Aspirational pursuit of mates in online dating markets. Science Advances, 4(8), eaap9815. https://doi.org/10.1126/sciadv.aap9815

Cheek, J. M. (1983). The Revised Cheek and Buss Shyness Scale (RCBS). Unpublished manuscript, Wellesley College, Wellesley, MA, USA.

Cheek, J. M., \& Buss, A. H. (1981). Shyness and sociability. Journal of Personality and Social Psychology, 41, 330-339. https://doi.org/10.1037/0022-3514.41.2.330

Centers for Disease Control and Prevention. (2017). National marriage and divorce rate trends. Retrieved from https://www.cdc.gov/nchs/fastats/marriage-divorce.htm

Crozier, W. R. (2005). Measuring shyness: Analysis of the revised Cheek and Buss Shyness scale. Personality and Individual Differences, 38, 1947-1956. https://doi.org/10.1016/j.paid.2004.12.002

Davidson, A. R., \& Jaccard, J. J. (1979). Variables that moderate the attitude-behavior relation: Results of a longitudinal survey. Journal of Personality and Social Psychology, 37, 1364-1376. https://doi.org/10.1037/0022-3514.37.8.1364

Donn, J. E., \& Sherman, R. C. (2002). Attitudes and practices regarding the formation of romantic relationships on the internet. Cyberpsychology \& Behavior, 5, 107-123. https://doi.org/10.1089/109493102753770499

Erikson, E. H. (1968). Identity: Youth and crisis. New York, NY, USA: W. W. Norton.

Finkel, E. J., Eastwick, P. W., Karney, B. R., Reis, H. T., \& Sprecher, S. (2012). Online dating: Critical analysis from the perspective of psychological science. Psychological Science in the Public Interest, 13, 3-66.

https://doi.org/10.1177/1529100612436522

Finkel, E. J., Hui, C. M., Carswell, K. L., \& Larson, G. M. (2014). The suffocation of marriage: Climbing Mount Maslow without enough oxygen. Psychological Inquiry, 25, 1-41. https://doi.org/10.1080/1047840X.2014.863723

Goodwin, R. (1990). Dating agency members: Are they 'different'? Journal of Social and Personal Relationships, 7, 423-430. https://doi.org/10.1177/0265407590073007

Henderson, L., Gilbert, P., \& Zimbardo, P. (2014). Shyness, social anxiety, and social phobia. In S. G. Hofmann \& P. M. DiBartolo (Eds.), Social anxiety: Clinical, developmental, and social perspectives (3rd ed., pp. 95-115). London, United Kingdom: Elsevier.

Hopko, D. R., Stowell, J., Jones, W. H., Armento, M. E. A., \& Cheek, J. M. (2005). Psychometric properties of the revised Cheek and Buss Shyness Scale. Journal of Personality Assessment, 84, 185-192. https://doi.org/10.1207/s15327752jpa8402_08

Houran, J., \& Lange, R. (2004). Expectations of finding a 'soul mate' within online dating. North American Journal of Psychology, 6, 297-308. 
Ickes, W. (2009). Strangers in a strange lab: How personality shapes our initial encounters with others. New York, NY, USA: Oxford University Press.

Jackson, T., Fritch, A., Nagasaka, T., \& Gunderson, J. (2002). Towards explaining the association between shyness and Ioneliness: A path analysis with American college students. Social Behavior and Personality, 30, 263-270. https://doi.org/10.2224/sbp.2002.30.3.263

Kim, M., Kwon, K., \& Lee, M. (2009). Psychological characteristics of internet dating service users: The effect of selfesteem, involvement, and sociability on the use of internet dating services. Cyberpsychology \& Behavior, 12, 445-449. https://doi.org/10.1089/cpb.2008.0296

Laumann, E. O., Gagnon, J. H., Michael, R. T., \& Michaels, S. (1994). The social organization of sexuality: Sexual practices in the United States. Chicago, IL, USA: University of Chicago Press.

Leck, K. (2006). Correlates of minimal dating. The Journal of Social Psychology, 146, 549-567. https://doi.org/10.3200/SOCP.146.5.549-567

LeFebvre, L. E., \& Carmack, H. J. (2019). Catching feelings: Exploring commitment (un)readiness in emerging adulthood. Journal of Social and Personal Relationships; Advance online publication. https://doi.org/10.1177/0265407519857472

LeSure-Lester, G. E. (2001). Dating competence, social assertion and social anxiety among college students. College Student Journal, 35, 317-320.

Manning, P., \& Ray, G. (1993). Shyness, self-confidence, and social interaction. Social Psychology Quarterly, 56, 178-192. https://doi.org/10.2307/2786777

Neff, L. A., \& Morgan, T. A. (2014). The rising expectations of marriage: What we do and do not know. Psychological Inquiry, 25, 95-100. https://doi.org/10.1080/1047840X.2014.878234

Orr, A. (2004). Meeting, mating, and cheating: Sex, love, and the new world of online dating. Upper Saddle River, NJ, USA: Reuters Prentice Hall.

Poley, M. E. M., \& Luo, S. (2012). Social compensation or rich-get-richer? The role of social competence in college students' use of the internet to find a partner. Computers in Human Behavior, 28, 414-419. https://doi.org/10.1016/j.chb.2011.10.012

Reis, H. T., Lin, Y. C., Bennett, M. E., \& Nezlek, J. B. (1993). Change and consistency in social participation during early adulthood. Developmental Psychology, 29, 633-645. https://doi.org/10.1037/0012-1649.29.4.633

Rosenfeld, M. (2018). Are Tinder and dating apps changing dating and mating in the USA? In J. Van Hook, S. McHale, \& V. King (Eds.), Families and Technology. National Symposium on Family Issues, 9, 103-117. Cham, Switzerland: Springer.

Rosenfeld, M. J., \& Thomas, R. J. (2012). Searching for a mate: The rise of the internet as a social intermediary. American Sociological Review, 77, 523-547. https://doi.org/10.1177/0003122412448050

Rosenfeld, M. J., Thomas, R. J., \& Hausen, S. (2019). Disintermediating your friends: How online dating in the United States displaces other ways of meeting. Proceedings of the National Academy of Sciences of the United States of America, 116, 17753-17758. https://doi.org/10.1073/pnas.1908630116 
Sassler, S., \& Miller, A. J. (2015). The ecology of relationships: Meeting locations and cohabitors' relationship perceptions. Journal of Social and Personal Relationships, 32, 141-160. https://doi.org/10.1177/0265407514525886

Scharlott, B. W., \& Christ, W. G. (1995). Overcoming relationship-initiation barriers: The impact of a computer-dating system on sex role, shyness, and appearance inhibitions. Computers in Human Behavior, 11, 191-204. https://doi.org/10.1016/0747-5632(94)00028-G

Schneier, F. R., Heckelman, L. R., Garfinkel, R., Campeas, R., Fallon, B. A., Gitow, A., . . Liebowitz, M. R. (1994). Functional impairment in social phobia. The Journal of Clinical Psychiatry, 55, 322-331.

Smith, A. (2016). 15\% of American adults have used online dating sites or mobile dating apps. Washington, DC, USA: Pew Internet and American Life Project.

Smith, A., \& Duggan, M. (2013). Online Dating \& Relationships. Retrieved from Pew Research Center website: https://www.pewresearch.org/internet/2013/10/21/online-dating-relationships/

Spielmann, S. S., MacDonald, G., Maxwell, J. A., Joel, S., Peragine, D., Muise, A., \& Impett, E. A. (2013). Settling for less out of fear of being single. Journal of Personality and Social Psychology, 105, 1049-1073. https://doi.org/10.1037/a0034628

Stephure, R. J., Boon, S. D., MacKinnon, S. L., \& Deveau, V. L. (2009). Internet initiated relationships: Associations between age and involvement in online dating. Journal of Computer-Mediated Communication, 14, 658-681. https://doi.org/10.1111/j.1083-6101.2009.01457.x

Valkenburg, P. M., \& Peter, J. (2007). Who visits online dating sites? Exploring some characteristics of online dater. Cyberpsychology \& Behavior, 10, 849-852. https://doi.org/10.1089/cpb.2007.9941

Wenzel, A., \& Emerson, T. (2009). Mate selection in socially anxious and nonanxious individuals. Journal of Social and Clinical Psychology, 28, 341-363. https://doi.org/10.1521/jscp.2009.28.3.341

Whitty, M. T., \& Buchanan, T. (2009). Looking for love in so many places: Characteristics of online daters and speed daters. Interpersona, 3, 63-86. https://doi.org/10.5964/ijpr.v3isupp2.76 